\title{
Is a leukoerythroblastic blood picture common in COVID-19-positive adults?
}

\author{
Navpreet Kaur, Sufian Zaheer*, Shruti Sangwan, Sunil Ranga \\ Department of Pathology, Vardhman Mahavir Medical College and Safdarjung Hospital, New Delhi, India
}

\section{Introduction}

The ongoing outbreak of coronavirus disease 19 (COVID-19), also known as novel coronavirus pneumonia, is a serious infectious disease and the latest threat to global health. This disease first appeared in Wuhan, China in early December 2019. Within two months it had spread all over the world, and is caused by severe acute respiratory syndrome coronavirus 2 (SARS-CoV-2). The structure of this virus is related to the virus which caused severe acute respiratory syndrome (SARS) and Middle East respiratory syndrome coronavirus (MERS) [1, 2]. This COVID-19 virus was initially thought to predominantly involve the respiratory tract, but later pathological changes in multiple organs were observed, including changes in the blood and complete blood picture [3].

Leukoerythroblastic reaction (LER) is defined as a condition in which immature erythroid and myeloid cells are seen circulating in the peripheral blood. It is typically seen in bone marrow fibrosis, myeloproliferative neoplasm, and bone marrow metastatic disorders [4]. LER is very rare, and uncommon in viral infections until this disease came into existence. Here we present three cases (institutional study) of COVID-19-positive patients showing LER.

\section{Material and methods}

This study was carried out at a tertiary care hospital in September 2020 to specifically observe the leukoerythroblastic reaction in the general blood picture of 45 patients admitted with COVID-19. The clinical, radiological, and hematological details of all the admitted COVID-19-positive patients were studied. After compiling the data of hematological observations, we came across three patients showing LER in peripheral blood smears. The clinical details, radiological findings, and laboratory findings of these three patients are set out in tabulated form. (Table I).

\section{Clinical presentation}

\section{Case 1}

COVID-19-positive 45-year-old male with a history of diabetes presented with influenza-like symptoms, which he had had for four days before admission, with no history of travelling abroad. Radiology showed lobar pneumonia; his symptoms worsened within two days and $\mathrm{pO}_{2}$ fell below 92\%; he was then intubated. On day 1 of admission, his complete blood picture $(\mathrm{CBC})$ showed hemoglobin within the normal range $(7.45 \mathrm{mmol} / \mathrm{L})$, a normal white blood cell (WBC) count i.e. $9.8 \times 10^{9} / \mathrm{L}$ and differential leucocyte count (DLC) showed decreased lymphocyte count $\left(1.7 \times 10^{9} / \mathrm{L}\right)$, 30-32 nucleated red blood cells (RBC)/100 WBC was also seen and the platelet count was within the normal range $\left(1.8 \times 10^{9} / \mathrm{L}\right)$ for age. On day 6 , he developed leukocytosis $\left(25 \times 10^{9} / \mathrm{L}\right)$ along with left-shifted myeloid cells (including occasional myelocytes and rare promyelocytes) along with immature erythroid cells (erythroblast). Monocytosis was also noted $\left(1.5 \times 10^{9} / \mathrm{L}\right)$. However, platelets were normal $\left(1.6 \times 10^{9} / \mathrm{L}\right)$ for age. RBC showed mild anisocytosis and rare dacrocytes (tear drop cells). Schistocytes were absent. No evidence of sepsis was noted on blood picture, and blood culture for sepsis was negative. The above picture was consistent with LER with a normocytic normochromic picture. Flow cytometry was advised to rule out any marrow infiltration. Bone marrow examination and flow cytometry showed normoblastic marrow reaction. No evidence of atypical cells or blasts was seen. After 20 days, the patient was clinically better and the hematology parameters had also come back to normal with resolution of neutrophilia.

\footnotetext{
*Address for correspondence: Sufian Zaheer, Department of Pathology, Vardhman Mahavir Medical College and Safdarjung Hospital, 405, VMMC College Building, Ring Road, New Delhi, India, phone +91 96505948 18, e-mail: sufianzaheer@gmail.com 
Table I. Clinical details, radiological findings, laboratory findings of three patients

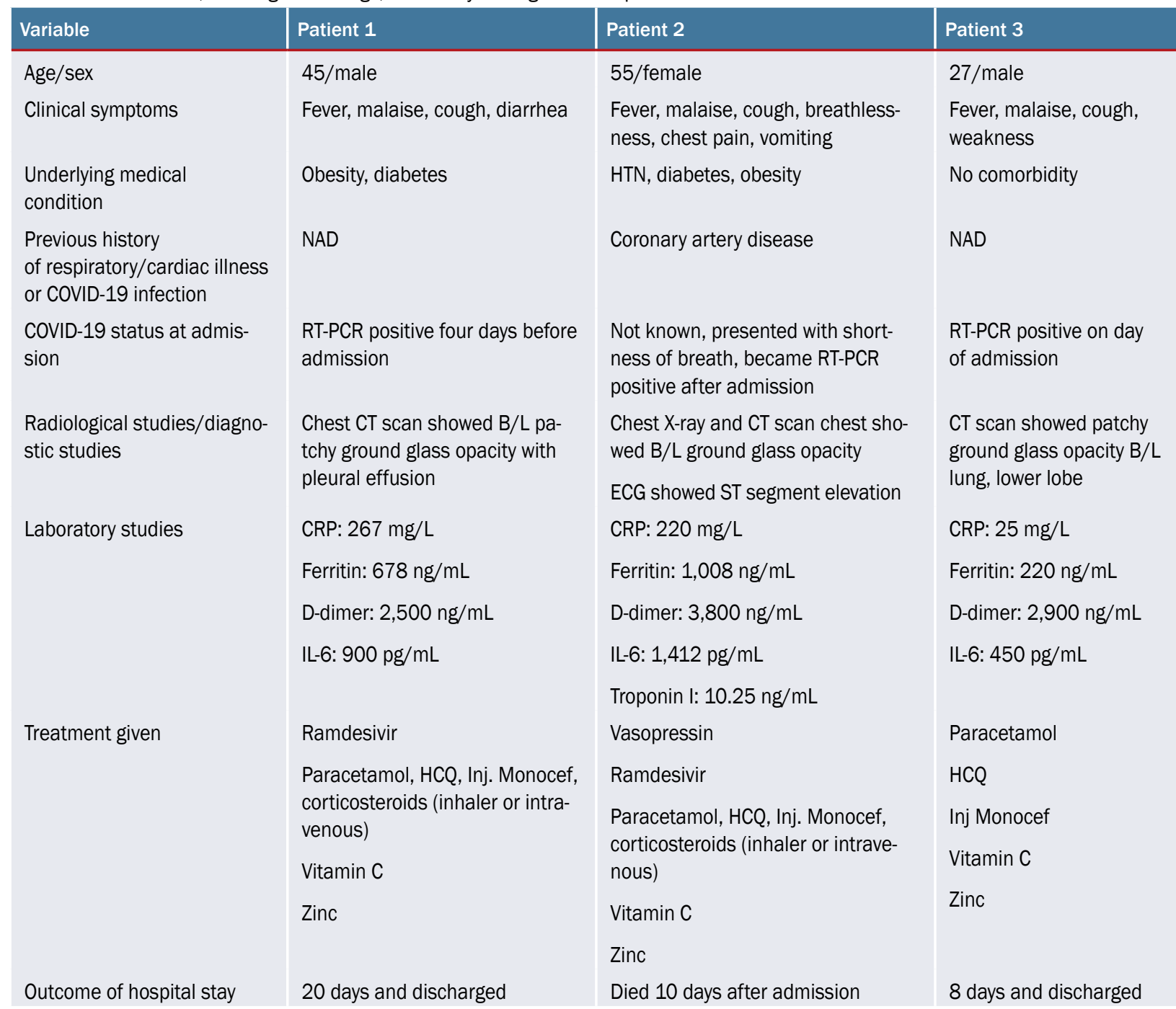

HTN - hypertension; NAD - no abnormality detected; RT-PCR - reverse transcriptase polymerase chain reaction; COVID-19 - coronavirus disease 19; CT scan - computed tomography scan; B/L - bilateral; ECG - electrocardiography; CRP - C-reactive protein; D-dimer - fibrin degradation fragment; IL-6 - interleukin 6; HCQ - hydroxychloroquine; inj. - injectable

\section{Case 2}

A 55-year-old obese female was admitted to the emergency department with fever, malaise, cough, breathlessness, chest pain, and vomiting. She was a known case of coronary artery disease (five years previously she had had angiography followed by angioplasty) with hypertension and diabetes. At the time of admission, her COVID-19 status was unknown. It was later discovered to be positive on a real-time reverse transcription-polymerase chain reaction ( $\mathrm{rRT}$-PCR) test. Chest X-ray and computed tomography (CT) scan showed bilateral ground-glass opacity and electrocardiogram (ECG) showed ST-segment elevation suggestive of myocardial ischemia. She was then transferred to intensive care unit and intubated. Her ferritin, C-reactive protein (CRP), and D-dimer levels were raised (Table I). Her basic hematology parameters showed hemoglobin $6.39 \mathrm{mmol} / \mathrm{L}$, raised whole blood cell count $\left(30 \times 10^{9} / \mathrm{L}\right)$, DLC showed decreased lymphocyte count $\left(4.5 \times 10^{9} / L\right)$, and $24-25$ nucleated RBC/100 WBC was also seen. The platelet count was within the normal range $\left(1.58 \times 10^{9} / \mathrm{L}\right)$. Monocyte count was mildly raised $\left(1.1 \times 10^{9} / \mathrm{L}\right)$. A shift to left of neutrophilic cells was noted (myelocyte, metamyelocyte, band form, and bilobed neutrophils) and immature RBC were also seen (erythroblast). All the features of sepsis-like toxic granules, dohle bodies, vacuolation were absent, and blood culture for sepsis was negative. The above picture is consistent with LER. Based on this report, clinicians advised bone marrow examination and flow cytometry, which showed normoblastic marrow, and no evidence of marrow infiltration was seen. Unfortunately, she died on the $11^{\text {th }}$ day.

\section{Case 3}

A healthy, fit 27-year-old junior resident doctor of our institution who hwas on duty in a COVID-19 ward in August 2020 presented with fever, malaise, cough, and weakness. 
He had no co-morbidity. On admission, his real-time reverse transcription-polymerase chain reaction (rRT-PCR) was positive for COVID-19. He had a fever of three days' duration, and onset of cough occurred on day 2 of admission. His hemoglobin was within the normal range (8.07 mmol/L), normal WBC count $\left(8.8 \times 10^{9} / \mathrm{L}\right)$ and DLC showed decreased lymphocyte count $\left(1.6 \times 10^{9} / \mathrm{L}\right)$ and the platelet count was towards the lower side of the normal range $\left(1.51 \times 10^{9} / \mathrm{L}\right)$, but his cough became increasingly severe. CT scan showed a patchy ground-glass pattern in the lower lobes of bilateral lungs. On day 8 , he developed leukocytosis $\left(25 \times 10^{9} / \mathrm{L}\right)$ along with a shift to left in neutrophilic cells (myelocytes, metamyelocytes and band forms) and 18-20 nucleated RBC/100 WBC were seen. Very mild monocytosis $\left(1 \times 10^{9} / \mathrm{L}\right)$ was also noted. Platelets were towards the lower side of the normal range $\left(1.48 \times 10^{9} / \mathrm{L}\right)$. All the features of sepsis were ruled out, including negative blood culture. Bone marrow examination and flow cytometry was advised. But on flow cytometry, normoblastic marrow was reported by two separate hematologists. So, the above picture was consistent with LER with normocytic normoblastic picture on bone marrow examination and flow cytometry. After 8 days of hospital stay, the patient was discharged as he had clinically improved, and also the hematology parameters had come back to normal.

\section{Discussion}

LER was first described by Weil and Clerc at the beginning of the $20^{\text {th }}$ century in metastatic malignancies [5]. The term 'leukoerythroblastic' was coined by Vaughn in 1936; the synonyms of this term are leukemoid reaction with normoblasts and leukoerythroblastosis [6]. It is defined as a condition in which there is a presence of immature myeloid cells and nucleated red blood cells in the circulating blood [4]. LER is most commonly seen in patients with metastatic malignancies, but Clifford was the first to describe it in conditions other than cancer, including hemolytic anemia, blood loss (acute or chronic), congestive heart failure, sepsis, megaloblastic anemia, and tuberculosis [5-7].

LER is usually not seen in viral infections, except for one study by Lemont et al. in 2011 that showed LER can rarely be seen in parvovirus B19 infection [8].

$A$ recent study by Mitra et al. on LER in patients with COVID-19 disease [4] supports our present study that LER can occur in COVID-19-positive patients. A similar study by Lee and Margolskee [9] showed leukoerythroblastosis and plasmacytoid picture in a seven-year-old child with multisystem inflammatory syndrome (MIS-C). Similarly, a study on multisystem inflammatory syndrome in adults (MIS-A) in SARS-CoV-2 infection was done by Morris et al. [10].
MIS-A is a complication of SARS-CoV-2 infection [11]. It is a rare condition, and to diagnose MIS-A the following criteria must be met:

1) Person $>21$ years who needs hospitalization in case of severe illness;

2) COVID-19 positive report of patient at admission or in the prior 12 weeks;

3) laboratory evidence of increased CRP, D-dimer, ferritin, and IL-6 levels;

4) no evidence of previous severe respiratory illness (to exclude patients with organ dysfunction or sepsis).

Studies have been done on MIS-A since COVID-19 came into existence. In our study, all three cases with LER fulfilled the above criteria of MIS-A, as they were all > 21 years and had COVID-19-positive reports with no previous severe respiratory illness, but with increased levels of CRP, D-dimer, and ferritin (Table I).

Furthermore, in our study, these three cases with MIS-A showed increased levels of IL-6. This was supported by Pierce et al. [11] who compared IL-6 levels of children and adults. They came to the conclusion that IL-6 levels play a significant role in MIS-A [11]. IL-6 level was markedly raised in all three cases, with the highest level $(1,412 \mathrm{pg} / \mathrm{mL})$ in case 2 (Table I).

In our study, the peripheral smear of these patients showed the presence of immature myeloid cells and nucleated red blood cells with mild anisocytosis in the circulating blood (Figure $1 \mathrm{~A}-\mathrm{C}$ and Figure 2). Smears of these patients also showed neutrophilia, which indicates that the body was producing leucocytes to fight the infection. However, contrary to this finding in SARS-CoV-2 infection, reactive lymphocytes are commonly seen in viral infections such as infectious mononucleosis, dengue fever, etc. In COVID-19 patients, lymphocytes showed abundant distinct pale blue cytoplasm with skirting of lymphocytes with abutting adjacent red blood cells. Smudge cells were also seen in case 1 and case 2 which is supported by the study by Jerez et. al. that smudge cells are seen in COVID-19 patients [12]. These features are consistent with the findings of leukoerythroblastic reaction.

\section{Limitations of study}

Our study is limited by the relatively small patient group and the single-center approach. As our understanding of this novel virus keeps evolving, the spectrum of disease, clinical manifestations, and pathophysiology underlying this infection will be enhanced over the coming months.

From the above study we conclude that in the current scenario, for future reference, if a patient presents with fever, cough, and pneumonia along with leukoerythroblastic reaction in peripheral smear, we should always try to rule out SARS-CoV-2 infection and advise COVID-19 testing rather than bone marrow examination and flow cytometry for 


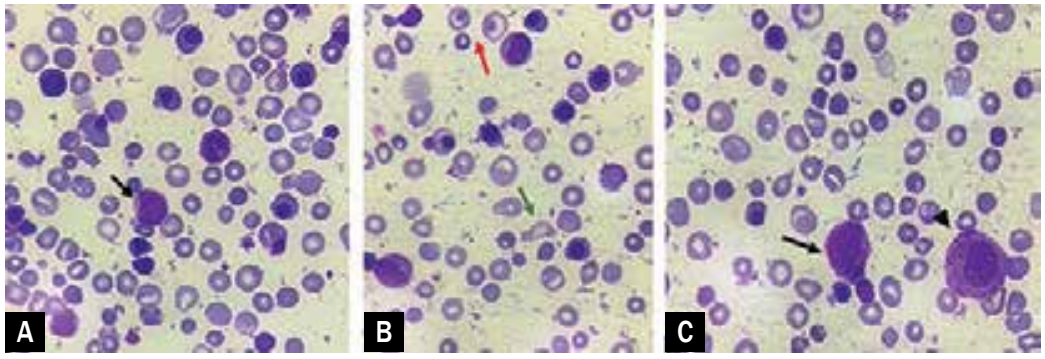

Figure 1A-C. Peripheral smear at 100x magnification: left shift of myeloid series showing myelocyte (arrow in figures A and C), metamyelocyte, (arrowhead figure $\mathrm{C}$ ) neutrophil along with immature late (orthrochromatic) erythroid precursors in background of mild anisopoikilocytosis showing microcytes, target cells (red arrow) and helmet cell (green arrow) (Leishman stain, 100x)

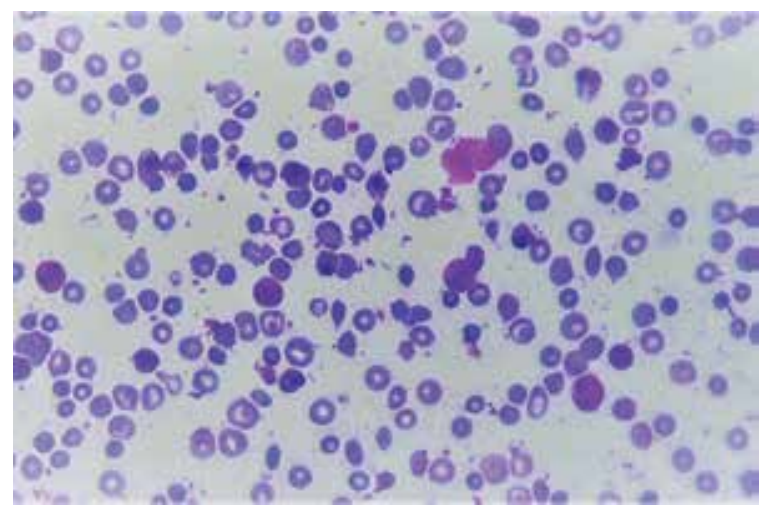

Figure 2. Peripheral smear at $100 \times$ magnification shows red blood cells (RBCs) showing microcytes, tear drop cells, target cells, helmet cells along with nucleated RBCs and left-shifted neutrophilic cells (Leishman stain, 100x)

suspected leukemia and malignancy workup. This is helpful in COVID-19 patients to avoid unnecessary blood workup and diagnostic tests.

\section{Authors' contributions}

SZ, NK helped in diagnosis of cases and clinico-pathological correlation. All authors contributed to writing and review of the manuscript.

\section{Conflict of interest}

None.

\section{Financial support \\ None.}

\section{Ethics}

The work described in this article has been carried out in accordance with The Code of Ethics of the World Medical Association (Declaration of Helsinki) for experiments involving humans; EU Directive 2010/63/EU for animal experiments; Uniform Requirements for manuscripts submitted to Biomedical journals.

\section{References}

1. Fauci AS, Lane HC, Redfield RR. Covid-19 - navigating the uncharted. N Engl J Med. 2020; 382(13): 1268-1269, doi: 10.1056/ /NEJMe2002387, indexed in Pubmed: 32109011.

2. Tian S, Xiong $\mathrm{Y}$, Liu H, et al. Pathological study of the 2019 novel coronavirus disease (COVID-19) through postmortem core biopsies. Mod Pathol. 2020; 33(6): 1007-1014, doi: 10.1038/s41379-020-0536-x, indexed in Pubmed: 32291399.

3. Wadman M, Couzin-Frankel J, Kaiser J, et al. A rampage through the body. Science. 2020; 368(6489): 356-360, doi: 10.1126/science.368.6489.356, indexed in Pubmed: 32327580.

4. Mitra A, Dwyre DM, Schivo M, et al. Leukoerythroblastic reaction in a patient with COVID-19 infection. Am J Hematol. 2020; 95(8): 999-1000, doi: 10.1002/ajh.25793, indexed in Pubmed: 32212392.

5. Clifford GO. The clinical significance of leukoerythroblastic anemia. Med Clin North Am. 1966; 50(3): 779-790, doi: 10.1016/s00257125(16)33177-7, indexed in Pubmed: 5325278.

6. Beattie JW, Withey JL. Polycythaemia, leuco-erythroblastosis, and myelosclerosis. Br Med J. 1953; 2(4833): 414-417, doi: 10.1136/ /bmj.2.4833.414, indexed in Pubmed: 13066741.

7. Tabares Calvache E, Tabares Calvache AD, Faulhaber GA. Systematic review about etiologic association to the leukoerythroblastic reaction. Int J Lab Hematol. 2020; 42(5): 495-500, doi: 10.1111/ijlh.13238, indexed in Pubmed: 32562368.

8. Lamont RF, Sobel JD, Vaisbuch E, et al. Parvovirus B19 infection in human pregnancy. BJOG. 2011; 118(2): 175-186, doi: 10.1111/j.14710528.2010.02749.x, indexed in Pubmed: 21040396.

9. Lee WS, Margolskee E. Leukoerythroblastosis and plasmacytoid lymphocytes in a child with SARS-CoV-2-associated multisystem inflammatory syndrome. Blood. 2020; 136(7): 914, doi: 10.1182/ /blood.2020007132, indexed in Pubmed: 32790856.

10. Morris SB, Schwartz NG, Patel P, et al. Case series of multisystem inflammatory syndrome in adults associated with SARS-CoV-2 infection - United Kingdom and United States, March-August 2020. MMWR Morb Mortal Wkly Rep. 2020; 69(40): 1450-1456, doi: 10.15585/ /mmwr.mm6940e1, indexed in Pubmed: 33031361.

11. Pierce CA, Preston-Hurlburt P, Dai Y, et al. Immune responses to SARS-CoV-2 infection in hospitalized pediatric and adult patients. Sci Trans। Med. 2020; 12(564), doi: 10.1126/scitransImed.abd5487, indexed in Pubmed: 32958614.

12. Jerez J, Ernst DM. High percentage of smudge cells in a patient with COVID19: rediscovering their utility. EJHaem. 2020 [Epub ahead of print], doi: 10.1002/jha2.52, indexed in Pubmed: 32838400. 